\title{
SOCIOLOGIA DA EDUCAÇÃO: O DEBATE AGÊNCIA $V E R S U S$ ESTRUTURA E A BUSCA PELO LUGAR DAS ORGANIZAÇÕES ESCOLARES A PARTIR DE NORBERT ELIAS ${ }^{1}$
}

\author{
SOCIOLOGY OF EDUCATION: THE AGENCY VS. STRUCTURE \\ DEBATE AND THE SEARCH FOR THE PLACE OF SCHOOL \\ ORGANIZATIONS FROM NORBERT ELIAS
}

\begin{abstract}
SOCIOLOGÍA DE LA EDUCACIÓN: EL DEBATE AGENCIA VERSUS ESTRUCTURA Y LA BÚSQUEDA POR EL LUGAR DE LAS ORGANIZACIONES ESCOLARES A PARTIR DE NORBERT ELIAS
\end{abstract}

JAMERSON MOURA $^{\text {I }}$

Resumo Desenvolvemos esse trabalho sob a luz da Teoria Sociológica dos Processos de Norbert Elias concebendo a escola como uma figuração, um elemento intermediário que recebe a influência de contextos de interação macro e microssociais. A análise resulta de nossa tese de doutorado e se debruça sobre os processos sociais pelos quais passaram os campos educacionais do Brasil e Portugal, países que implementaram políticas de gestão democrática da educação após vivenciarem regimes autoritários, mas que cederam espaço a outras políticas de gestão escolar. Questionamos: a cultura organizacional sedimentada nas escolas desses dois campos poderia constituir um fator de resistência ao processo de implementação de políticas públicas? Qual a orientação epistemológica mais adequada para tratar de organizações escolares? Com a sociologia histórica, processual e figuracional eliasiana entendemos que a mudança deixa de ser necessariamente algo superior e coercitivo, devendo ser vista como inerente às relações sociais. Nesse sentido, a convivência de

Universidade Federal de Pernambuco (UFPE), Recife/PE - Brasil.

Esse artigo é resultado de nossa tese de doutorado desenvolvida no Departamento de Sociologia da Universidade Federal de Pernambuco e contou com financiamento da CAPES (Coordenação de Aperfeiçoamento de Pessoal de Nível Superior) para a realização de Doutorado Sanduíche no Centro de Estudos Sociais da Universidade de Coimbra, Portugal. 
muitos dos atores sociais das organizações escolares com o período ditatorial fê-los desenvolver práticas autoritárias em suas relações socioprofissionais, nos levando a dar importância à sociogênese dos processos que se relacionam com as escolas, vendo os indivíduos como membros de uma teia de relações compostas não só por regras determinadas e rígidas como também por necessidades e escolhas individuais.

Palavras-chave: Teoria Sociológica dos Processos. Política de Gestão Democrática da Educação. Figurações Escolares. Cultura Organizacional Escolar.

Abstract We develop this work in the light of Norbert Elias' Sociological Theory of Processes, conceiving the school as a figuration, an intermediary element that receives the influence of macro and microssocial interaction contexts. The analysis results from our doctoral thesis and deals with the social processes through which the educational fields of Brazil and Portugal passed, countries that implemented policies of democratic management of education after experiencing authoritarian regimes, but which gave way to other school management policies. The organizational culture sedimented in the schools of these two fields could constitute a factor of resistance to the process of implementation of public policies? What is the most appropriate epistemological orientation for dealing with school organizations? With the Eliasian historical, procedural and figurative sociology, we understand that change is no longer necessarily superior and coercive, and must be seen as inherent in social relations. In this sense, the coexistence of many of the social actors of school organizations with the dictatorial period led them to develop authoritarian practices in their socio-professional relations, leading us to give importance to the sociogenesis of processes that relate to schools, viewing individuals as members of a web of relations composed not only by determined and rigid rules but also by individual needs and choices.

Keywords: Sociological Theory of Processes. School Organizational Culture. School Figurations. Democratic Management of Education’s Policy.

Resumen Desarrollamos este trabajo bajo la luz de la Teoría Sociológica de los Procesos de Norbert Elias concebiendo la escuela como una figuración, un elemento intermedio que recibe la influencia de contextos de interacción macro y microsocial. Los resultados del análisis de nuestra tesis doctoral y se centra en los procesos sociales por los que pasan los cursos educativos en Brasil y Portugal, países que han aplicado políticas de gestión democrática de la educación después de que experimentan los regímenes autoritarios, pero dieron paso a otras políticas de gestión de la escuela. ¿Cuestionamos: la cultura organizacional sedimentada en las escuelas de estos dos campos podría constituir un factor de resistencia al proceso de implementación de políticas públicas? ¿Cuál es la orientación epistemológica más adecuada para tratar a las organizaciones escolares? Con la sociologia histórica, procesal y figuracional eliasiana compreendiemos que el cambio deja de ser necesariamente algo superior y coercitivo, debiendo ser visto como inherente a las relaciones sociales. En ese sentido, la convivencia de muchos de los actores sociales de las organizaciones escolares con el período dictatorial los hizo desarrollar prácticas autoritarias en sus relaciones socioprofesionales, llevándonos a 
dar importancia a la sociogénesis de los procesos que se relacionan con las escuelas, viendo a los individuos como miembros de los miembros una red de relaciones compuestas no sólo por reglas determinadas y rígidas, sino también por necesidades y elecciones individuales.

Palabras clave: Teoría Sociológica de los Procesos. Política de Gestión Democrática de la Educación. Figuraciones Escolares. Cultura Organizacional Escolar.

\section{INTRODUÇÃo}

Consideramos que o êxito de uma política pública também depende de como ela é dinamizada pela imbricada rede de relações de interdependência que se desenvolvem entre os diversos atores do campo educacional. Tomamos como premissa a ideia de que, mesmo em se tratando de políticas propositivas, o desenvolvimento das políticas também dependerá dos processos sociais que envolvem sua formulação e implementação.

Analisamos, então, como se deu a apropriação e viabilização da política de Gestão Democrática da Educação em escolas que compartilham culturas organizacionais advindas de práticas socioprofissionais ainda ligadas ao autoritarismo (consequência de sociedades que foram governadas por regimes autoritários) associadas a práticas socioprofissionais e novas demandas sociais oriundas de processos de redemocratização política.

Concentramos nossa análise nas principais mudanças pelas quais passaram os campos educacionais do Brasil e Portugal. Esses dois campos apresentam pontos convergentes. Ambos se situam em países que implementaram políticas de gestão democrática da educação após vivenciarem regimes autoritários (o Brasil na década de 1980 e Portugal na década de 1970). Entretanto, posteriormente, esses campos educacionais cederam espaço a outras políticas de gestão escolar. Os objetivos da política de gestão democrática da educação foram alcançados ou os interesses políticos de atores não democráticos se sobrepuseram a eles?

No Brasil, o processo de democratização foi incorporado ao debate educacional, mas passou por diferentes entendimentos no transcorrer do último século. Inicialmente, democratização significava ampliação do acesso à escola pública; posteriormente, permanência na escola. Contudo, a partir da década de 1980, progressivamente, foram sendo incluídos elementos relacionados à descentralização da gestão de políticas educacionais, municipalização, qualidade do ensino, formação, valorização dos salários e condições de trabalho dos profissionais da educação (WEBER, 2004).

O desenvolvimento desse processo promoveu a criação de instâncias diversas - como conselhos municipais, colegiados e grupos gestores - visando a uma maior participação popular e a um maior controle e fiscalização das ações realizadas por secretarias de educação, antecipando políticas que viriam a ser legitimadas pela Constituição Federal de 1998 e a Lei de Diretrizes e Bases da Educação de 1996.

A Secretaria de Educação de Pernambuco foi uma das primeiras a se envolver nesse processo. Seguindo diretrizes que primavam pela universalização da educação básica com qualidade, a dignificação do trabalho do educador e a democratização da gestão educacional, essa Secretaria submeteu a debate, já em 1987, a implantação desses procedimen- 
tos por meio dos Fóruns Itinerantes de Educação: "canais de interlocução que permitiam apreender as aspirações e interesses da comunidade escolar e dos setores organizados da população" (AGUIAR, 2014).

Tais fóruns contaram com a participação de professores, pais, alunos, sindicatos, associações e outras entidades. Como era de se esperar, alguns dos temas levantados nos fóruns geraram polêmica e resistência, a exemplo do que tratava da forma de escolha dos diretores escolares e que visava reduzir o número de indicações de caráter político-partidário influenciadas por fisiologismo e clientelismo. Nesse sentido, a Secretaria de Educação (gestões de 1987-1990 e 1995-1998) propôs a convivência com várias maneiras de escolha de diretores, inclusive, incentivando a eleição direta pela própria comunidade escolar, forma que se tornou comum a todas as escolas a partir do ano de 2001.

A atual Secretaria de Educação determina, entretanto, que a escolha do diretor escolar só pode ser realizada após a elaboração de uma Lista Tríplice de candidatos que tenham sido aprovados em cursos de formação conduzidos exclusivamente pela Secretaria (Lei $\mathrm{n}^{\circ}$. 13.103/2012). Assim, somente após aprovação no curso de formação (com carga horária de 180 horas) é que o candidato poderá concorrer com outros dois nomes pela preferência da comunidade escolar. Todavia, ser o candidato mais votado não garante a nomeação, pois a decisão final sobre quem será nomeado diretor caberá ao governador do Estado.

No que diz respeito a Portugal, destacamos que a política de Gestão Democrática da Educação também foi implementada após o fim do regime autoritário que governou o país por cinco décadas e que, assim como ocorreu no Brasil, a implementação dessa política passou por processos sociais, enfrentando a resistência de atores sociais forjados ou beneficiados pelas práticas anteriores.

Os processos sociais que inicialmente se sucederam à implementação da política de gestão democrática até que incentivavam o desenvolvimento desse tipo de gestão. Focados em desenvolver uma maior autonomia escolar, esses primeiros processos sociais propunham mais descentralização das estruturas, maior participação de diferentes atores sociais, elegibilidade e colegialidade.

Contudo, outros processos sociais sucederam essa política e o sistema educacional português passou a pautar-se em uma regulação burocrática, baseada no cumprimento de normas e avaliação de resultados, dando margem à formulação e implementação da política de Agrupamento de Escolas (BARROSO, 2006). Dentre outros objetivos, essa política de agrupamentos procura reunir várias unidades de ensino em torno da administração de uma única escola-sede, desenvolvendo um espírito de concorrência e ranqueamento entre os agrupamentos e não mais estimulando a colaboração e participação entre as escolas e comunidades.

Dessa maneira, a partir da implementação da política de gestão democrática da educação, a organização do sistema educacional português vivenciou um estágio inicial de democratização e descentralização até chegar ao atual estágio de centralização e padronização das atividades. Segundo Lima (2004, p. 22), o sistema educacional português tornou-se um "sistema centralizado-desconcentrado, onde o que é relevante é a escola-sede, mas nem tanto o agrupamento e, muito menos, as escolas que o compõem". 
Diante do exposto, levantamos, então, as seguintes questões: haveria ainda algum ranço comportamental não democrático nas culturas organizacionais escolares dos dois campos? Tal ranço influenciaria a apropriação e viabilização das políticas de gestão democrática da educação? Qual orientação epistemológica das ciências sociais pode nos ajudar a melhor compreender a dinâmica de relações que se desenvolve entre atores sociais e organizações escolares?

\section{Agência x Estrutura: qual o lugar das Organizações Escolares?}

A análise da relação entre indivíduo e sociedade pode ser entendida como o principal objeto de estudo da Sociologia, o que não significa que as abordagens sobre ela se apresentem de maneira homogênea. Lembremos que, por um longo período, a estrutura social foi vista como definidora do comportamento dos indivíduos e principal eixo da análise sociológica.

Só para tomar como referência os pensadores clássicos, temos em Émile Durkheim, o entendimento de que a sociedade seria mais do que a soma de seus indivíduos, ela seria o mais importante elo entre forças naturais e morais, enquanto cada indivíduo seria apenas uma ínfima parte dela, membro de gerações anteriores a ele próprio que, além de já terem desaparecido, continuarão a desaparecer, diferentemente da estrutura social.

Em As Formas Elementares da Vida Religiosa (2003), Durkheim toma a religião não como um simples artefato tradicional das culturas, mas como um fato social simbólico, um ritual de crença que, por ser praticado em coletividade, causa impacto na noção de solidariedade entre as pessoas e em sua organização social. A partir dessa análise, Durkheim desenvolve, ainda, os conceitos de Solidariedade Mecânica e Solidariedade Orgânica.

Esta seria a base para o seu conceito de Morfologia Social: aquilo que indicaria a força das relações estruturais entre as pessoas, a partir dos processos ritualísticos que envolvem indivíduos. Para Durkheim, a análise sociológica do simbolismo dos rituais e de uma sistematização das noções de sua representação poderia explicar a influência da estrutura sobre um determinado contexto sociocultural. Enquanto sistema de valores, o simbolismo se configuraria como reflexo da influência de uma moral social nos membros de uma coletividade que, por sua vez, agiriam guiados por determinados paradigmas.

Em termos de influência da estrutura na composição das relações sociais, encontramos no pensamento marxista semelhante entendimento. A partir do estudo histórico-econômico que realizou sobre importantes sociedades e sobre o sistema capitalista econômico, Karl Marx desenvolveu os conceitos de Infraestrutura e Superestrutura para a elaboração de suas análises.

A partir desses conceitos, a sociedade passa a ser comparada a uma construção cujas fundações (infraestrutura) seriam representadas pelas forças econômicas, enquanto a obra em si mesma (superestrutura) representaria as ideias, costumes e instituições da sociedade (MARX, 1996). Enquadrado na Teoria do Conflito, Marx entende que, na vida social, os indivíduos procuram dominar outros indivíduos por meio do controle das estruturas sociais citadas. 
Para Marx, esse controle também se dá pelo fato de as ideias dominantes de uma determinada época serem forjadas na ideologia da classe social que domina a sociedade. Essa dominação aliena os indivíduos de tal maneira que eles próprios reforçam as formas de dominação às quais se submetem. Em outras palavras, a sociologia marxista compreende que o indivíduo é diretamente influenciado pela estrutura social ao qual está vinculado.

É na sociologia de Max Weber (2002) que encontramos a ideia de que a sociedade não é algo superior, exterior, coercitivo e determinante do comportamento dos indivíduos, mas o resultado de uma enorme rede de interações interindividuais. Em termos weberianos, a sociedade não é aquilo que pesa sobre os indivíduos, mas o que se veicula entre eles, pois um mesmo meio cultural pode assumir significados diferentes para os diferentes indivíduos que nele estão inseridos.

Nesse sentido, Weber amplia a análise sociológica, indo além das estruturas totalizantes de uma sociedade - a exemplo do sistema econômico capitalista - e desenvolve o conceito de Ação Social. Com esse conceito, entende-se que a ação social explicaria diferenças de comportamento dos indivíduos a partir do modo de assimilação e dos diferentes tipos de racionalidade empregados pelos participantes de uma mesma cultura.

No texto Sobre algumas categorias da sociologia compreensiva (1913), Weber assim explica o conceito de Ação Social:

\footnotetext{
Por ação (incluindo a omissão e a tolerância) entendemos sempre um comportamento compreensível com relação a objetos, isto é, um comportamento especificado e caracterizado por um sentido (subjetivo) "real" ou "mental", mesmo que ele não seja quase percebido. [...] A ação que especificamente tem importância para a sociologia compreensiva em particular é um comportamento que: 1) Está relacionado ao sentido subjetivo pensado daquele que age com referência ao comportamento de outros; 2) Está codeterminado no seu decurso por esta referência significativa c, portanto, 3) Pode ser explicado pela compreensão a partir deste sentido mental (subjetivamente) (WEBER, 1913).
}

A realidade é concebida por Weber como o encontro entre os homens na forma como eles se vinculam e articulam modos convergentes no plano subjetivo. Assim, a sociologia deve ser capaz de captar a relação entre os homens e os valores no seio da vida cultural por meio das variadas formas de ação social. Inferimos, pois, que a compreensão (verstehen) dos significados culturais de um dado grupo social por parte dos indivíduos constitui um importante elemento da concepção weberiana. Isso porque Weber considera que tão importante quanto estudar a influência do sistema econômico é analisar os aspectos religiosos, militares, geográficos e as características da administração burocrática das instituições, estados modernos, partidos políticos e outras dimensões sociais.

Baseada na teoria levantada pelos três clássicos acima citados, a Sociologia foi sendo desenvolvida e aplicada em diversas áreas do conhecimento. Em termos de história da Teoria Social, destacamos que a análise das relações dos indivíduos em sociedade passou a ser interpretada a partir de outras variáveis epistemológicas. Representante da escola inglesa, o sociólogo Anthony Giddens (2003) analisa as relações sociais em termos de Estruturação 
e Práxis Social, entendendo que não se pode negar a força que os processos históricos desenvolvem enquanto influência nas práticas sociais.

As relações sociais [...] estão envolvidas na estruturação da interação, mas são também os principais 'blocos de construção' em torno dos quais as instituições se articulam na integração dos sistemas [...] As relações sociais dizem respeito ao 'posicionamento' dos indivíduos no bojo de um 'espaço social' de categorias e vínculos simbólicos. As regras envolvidas nas posições sociais têm normalmente algo a ver com a especificação dos direitos e obrigações pertinentes as pessoas dessas regras, em outras palavras, são particularmente pronunciadas, mas também a eles se aplicam todas as características anteriormente declaradas das regras. (GIDDENS, 1985, p. 89).

Essa reflexão Giddens procurou desenvolver em torno de um debate com a teoria de George Homans (1974), a propósito do que ficou conhecido como a Lei de Homans, que pode ser assim compreendida:

Quanto mais os indivíduos interagem, tanto mais se tornam parecidos e tendem a conformar-se a um padrão comum. Em outras palavras, se determinado grupo de pessoas é reunido de modo a ter que interagirem - trabalhando em um mesmo lugar, vivendo no mesmo bairro ou vila -, elas começam a formar um grupo coeso; elas desenvolvem uma cultura de grupo que não existia anteriormente, e inculcam seus padrões sobre cada indivíduo (COLLINS, 1999, p. 118).

Essa lei corrobora o que Giddens considerou na citação anterior: a coesão social depende da homogeneidade de características socioculturais entre os membros de um determinado grupo, segundo critérios de identificação social, práticas comportamentais e interesses comuns. Caso contrário, a coesão só seria possível pelo exercício da autoridade.

Tomando um agrupamento de trabalhadores em uma fábrica, Homans percebe que eles tendem a trabalhar em torno de meios e objetivos comuns, mas sem identificação coletiva a respeito de seus chefes ou supervisores. Se interagirem com eles, será apenas por obediência, tolerância e interesse em recompensas, mas, ainda assim, de maneira limitada, não se identificando e se relacionando mais fortemente com essas autoridades.

A razão pela qual os indivíduos se assemelham uns aos outros e, portanto, influenciam uns aos outros, só pode ser explicada pelo fato de que oferecem aos outros, algo que estes consideram gratificante. Esse algo é a recompensa fundamental da aprovação social. [...] Quando uma pessoa possui o poder de dar ordens, as outras pessoas a evitam, uma vez que esse tipo de interação não traz recompensas. Ambos os tipos de evidência são enquadradas no mesmo princípio: as pessoas pautam suas interações conforme as condições que garantem as melhores recompensas (idem, p. 119).

Identificado com as perspectivas do Interacionismo Simbólico, o canadense Erwin Goffman analisa os processos de interação social a partir do seu cotidiano e de uma abor- 
dagem microinteracionista de perspectiva dramática. Para ele, o mundo social poderia ser entendido a partir de uma analogia com o teatro, onde cada indivíduo teatralizaria as circunstâncias em que se encontra. Essa interpretação teatral seria marcada por rituais e posições que possibilitam distinguir indivíduos e grupos (GOFFMAN, 2007).

Goffman entende ser a partir dos encontros cotidianos teatralizados que o ritual social cria o eu de cada indivíduo. Nesse sentido, o desempenho dos papéis sociais teria a ver com o modo como cada indivíduo concebe a sua imagem e pretende mantê-la. A pertença a uma classe social, por exemplo, se marcaria por meio de ritualizações que distinguem indivíduos e grupos, considerando-se aspectos sutis, como as formas de se vestir ou de se apresentar publicamente. Essa interação deve ser entendida como um processo fundamental de identificação e de diferenciação dos indivíduos e grupos em relação ao poder.

Para Goffman, os rituais de interação social, análogos ao teatro, podem ser entendidos por meio da relação conceitual que desenvolveu entre palco e bastidor. O pensador diz que "nós realizamos performances, mas elas exigem a utilização de um figurino e de um cenário reais: roupas, o palco, uma plateia e um lugar onde os atores podem guardar seus equipamentos" (idem, p. 191).

Exemplo disso é a relação da vitrine de uma loja (palco), ponto de atração do cliente, com a parte de trás do balcão de vendas (bastidor), local onde os vendedores dividem seus territórios de atuação, estabelecem porcentagem de vendas e comportam-se de maneira mais informal. Essa analogia também foi aplicada à relação entre trabalhadores e administradores de fábricas, quando se notou que os operários adotavam um tipo específico de desempenho ao perceberem-se supervisionados e outro tipo, mais informal, quando se encontravam apenas entre seus pares.

A análise goffmaniana ainda nos traz a ideia de Frame, segundo a qual, mesmo que o mundo se torne bastante complexo, ele tende a ser edificado a partir da repetição de um pequeno número de mecanismos autômatos norteados por marcos primários. Para Goffman (2006), o enquadramento serviria para a análise de algum tipo de acontecimento em um marco de referência composto por relações culturais que se dão entre agentes e forças sociais, pois mesmo acontecimentos isolados no mundo social podem ser apreendidos a partir da instrumentalização analítica com base em frames. Goffman ainda considera que, embora por algum motivo haja a ruptura desse enquadramento, pode-se analisar a nova situação a partir de novos enquadramentos que se estendem às circunstâncias as quais possibilitaram e criaram a situação inesperada.

Por sua vez, Piotr Sztompka destaca que a vida social é regulada por regras, normas, valores e instituições que regulam a conduta humana e, diante dessa constatação, concebe a organização social como aquilo que "se baseia em normas coletivamente reconhecidas e aceitas que regulam não só as ações como também as experiências e representações de seus membros" (2005, p. 423).

O pensador polonês tem como finalidade provar a possibilidade de modificação dessas estruturas normativas a partir do que ele chama de Transgressão Institucionalizada de Regras. Para esse autor, a mudança pode ser produzida, de maneira incremental ou peremp- 
tória, por agentes que empreendem uma reforma normativa na vida cotidiana das pessoas comuns e nas organizações com as quais se relacionam.

Entusiasta da Teoria da Mudança Social, Stompka entende que as sociedades vivenciam constantes estágios de mudança. Todavia, conforme sua concepção, esses estágios de mudança não precisam necessariamente acontecer segundo uma lógica linear e evolutiva. Na verdade, a mudança, para ele, tende a ocorrer de maneira dialética, pois ela depende tanto da ação indefinida dos indivíduos quanto da especificidade de diferentes contextos sociais e históricos.

De acordo com essa concepção, não seria possível compreender a mudança de forma previsível e estável como também não se pode considerar a grande possibilidade de que ela possa se dar a qualquer momento e constantemente.

\begin{abstract}
Traduzindo para os termos de nosso modelo, isso significa que as transformações históricas abarcam apenas os agentes, a estrutura e a agência, não apenas as ações, as operações e a práxis, não apenas os ambientes da natureza e da consciência, mas também as ligações entre eles, os modos como se combinam para produzir a dinâmica social. Em resumo, eu sustento que, com a passagem do tempo, os próprios princípios de operação e o modo de funcionamento e mudança da sociedade humana sofrem transformações significativas (STOMPKA, 2005, p. 388).
\end{abstract}

Mediante o debate apresentado até aqui e analisando a dificuldade decorrente da dicotomia entre agência e estrutura para uma melhor compreensão das relações que envolvem as organizações e indivíduos inseridos no campo educacional, sugerimos a análise dos trabalhos de Norbert Elias, os quais apresentaremos a seguir.

Em seus trabalhos, Elias discorre sobre a ideia de que a sociedade não poderia ser vista apenas como a soma de vários indivíduos, assim como o indivíduo não deveria ser entendido como determinado totalmente pela sociedade. Na medida em que as sociedades se tornam mais complexas, mais desenhos de normas sociais são engendrados e, consequentemente, vislumbram-se mais possibilidades de entender-se o indivíduo, pois será a historicidade de cada um deles, aliada ao fenômeno do crescimento até a fase adulta, a chave para a compreensão do que seria sua sociedade (ELIAS, 1994).

Muito da sociologia eliasiana tem inspiração em Georg Simmel (WAIZBORT, 2001). Observemos que, se Simmel desenvolve sua análise sociológica, observando as diversas e específicas formas de socialização entre indivíduos e grupos, Elias faz algo semelhante ao voltar sua sociologia para a análise das redes de interdependência entre indivíduos e sociedade, por exemplo. Na sociologia de ambos, o social deve ser compreendido como um conjunto de relações.

Tais relações são sempre relações em processo, isto é: elas se fazem e desfazem, se constroem, se destroem, se reconstroem, são e deixam de ser, podem se refazer ou não, se rearticular ou não [...] mas, como quer que seja, há a cada instante algo vivo, em processo (idem, p. 92). 
Simmel chama atenção para o fato de que, no campo das ciências sociais de sua época, havia um problema particular: em detrimento da sociedade, o indivíduo é tido como algo concreto e, por isso, foco central de análise, enquanto à sociedade seria dado um papel secundário. Por isso, no livro Questões fundamentais da Sociologia (2006), ele questiona: seria a sociedade objeto da existência humana ou simplesmente um meio para o indivíduo?

Simmel entende que indivíduo e sociedade devem ser pensados de forma única, já que os processos sociais subjacentes à sociação precisam ser o que realmente deve ser levado em consideração pela análise sociológica, pois nem a sociedade é capaz de determinar todas as relações sociais, tampouco os indivíduos podem ser tomados como determinantes exclusivos (SIMMEL, 2006).

Para Simmel, sociação significa "relação/interação entre os indivíduos em seu cotidiano" (FONTES, 2012 p. 102). Assim, a sociedade representaria o que é feito pelos indivíduos para os indivíduos a partir de laços de interação que, de maneira contínua, são desfeitos e renovados, limitados ou expandidos, em um ininterrupto processo de sociação.

Para a sociologia simmeliana, é importante considerar que o processo de complexificação das sociedades causa a perda de vínculos comunitários, daí ser importante que elas sejam estudadas a partir da forma como os diversos fenômenos sociais que as compõem se estruturam. Em outras palavras, o estudo das sociedades deve partir da análise das "estruturações mais perenes e constitutivas de fenômenos de mesma natureza que, por sua vez, se manifestam, em inumeráveis ocasiões, sob condições particulares” (idem, p. 100).

Além disso, a análise sociológica deve se preocupar com a adequação de um método pertinente às realidades sociais específicas a serem pesquisadas, definindo categorias de análise que deem conta de modos formais de comportamento (SIMMEL, 2006). Justifica-se, dessa forma, a sua busca por entender o social a partir das "interações entre os homens ao nível micrológico: o salão, a coquete, o estranho, o passeio e muito mais" (WAIZBORT, 2001, p. 96).

\begin{abstract}
Além daqueles fenômenos perceptíveis de longe, que se impõem por toda parte devido a sua abrangência e importância externa, há um número imenso de formas menores de relação e de modos de interação entre os homens, em casos singulares aparentemente insignificantes, mas que são representados por esses casos singulares em uma medida nem um pouco desprezível, e que, na medida em que elas se movem por entre as amplas formações sociais, por assim dizer oficiais, realizam na verdade a sociedade, tal como nós a conhecemos (SIMMEL apud WAIZBORT, idem, p. 93).
\end{abstract}

Na obra Inquiries into the construction of social forms (2009), Simmel constata que os indivíduos se comportam relativamente indiferentes às particularidades de sua individualidade, conformando-se, assim, com relações nem sempre desejadas, a exemplo daquelas ligadas à família e ao parentesco. Contudo, como a cada indivíduo cabe uma história particular, uma possível progressão de suas ações individuais independentes o levará a relações de associação com círculos sociais mais heterogêneos. Dessa maneira, ele passará a desen- 
volver associações com indivíduos e grupos com base na identificação de similaridade e de interesses ou atividades comuns.

Para ilustrar seu argumento, Simmel cita o exemplo de como a nacionalidade se apresenta como um elo inicial para o estabelecimento de relações entre estudantes nas universidades. Depois do estabelecimento inicial dessas relações, é provável que, mais tarde, esses estudantes passem a estabelecer suas relações com base na identificação de áreas de pesquisa e de interesses comuns. Por outro lado, a nacionalidade pode se apresentar como um entrave inicial para o estabelecimento de relações sociais.

A título de exemplo, Simmel cita a relação entre trabalhadores de um determinado país que precisam conviver com trabalhadores estrangeiros por conta de uniões comerciais entre empresas internacionais. Para os primeiros, a exclusão dos estrangeiros seria o comum, contudo essa situação tende a ser substituída gradualmente pela obrigação de que todos precisem trabalhar juntos, independentemente da nacionalidade, durante as longas viagens nas embarcações.

Nesse sentido, levando-se em conta o local ou algum outro vínculo de determinação livremente escolhido, também se pode observar que a construção de grupos sociais se dá com base em relações práticas, sendo profícuo que a sociologia compreenda como ocorrem essas formas de associação. Para dar consistência a esse argumento, Simmel apresenta outros exemplos. Lembra que, na Grécia antiga, o vínculo de sangue e parentesco era determinante para a tomada de decisões do clã e a composição do governo. Contudo, tomar decisões com base nesses critérios não era garantia de fazer-se a melhor opção, tampouco certeza de alcançar a vitória.

Simmel destaca que isso acontecia em quase toda a Grécia, mais especificamente em Esparta, porém os interesses dos membros do clã estavam vinculados, prioritariamente, aos objetivos de alcance da vitória militar, sobrepondo-os, assim, aos interesses que se vinculassem a questões de parentesco. Não é, pois, por acaso que essa cidade se tornou conhecida por suas vitórias militares.

"Em Esparta havia cerca de 220 partidos políticos que se identificavam das mais diversas formas: juventude, pioneiros, anciãos" (SIMMEL, 2009, p. 368). Para Simmel, esse tipo de organização social era possível porque a cultura desenvolvida por aquela sociedade não tinha um dispositivo extensivo e objetivo sobre o controle das ideias e valores morais que se configurassem como hegemônicos, permitindo a presença dos interesses de grupos minoritários e possibilitando decisões de governo mais criteriosas.

$\mathrm{Na}$ análise que fez das relações sociais em comunidades aborígenes da Austrália, Simmel enfocou a constituição das relações em contextos que envolviam conflitos e disputas entre indivíduos de diferentes tribos pelo controle dos totens e a prática de sexo entre indivíduos que tinham grau de parentesco. Impressionado com as formas díspares e critérios de organização social diferentes das que estava habituado a analisar, Simmel argumenta que

for these wretched beings, who are not at all capable of an actually rational manner of association, such groupings by duality of affiliation, so sharply sepa- 
rated, directed more-or-less horizontally and vertically, must mean an enrichment in the feeling of being alive, an otherwise probably unreachable stretching and, so to speak, doubling of existence (idem, p. 367)2.

Apesar das fortes expressões por ele usadas, Simmel pondera que a antítese do processo de associação entre indivíduos e grupos, entre aquilo que é orgânico e o que é racional, classifica-se pelo desejo pessoal e natural de determinação nos estágios de vida social. Exemplo dessa influência verifica-se no poder exercido pela estrutura sobre indivíduos orientados a concordar, de maneira orgânica, com os pontos de vista dos membros mais antigos do grupo social ao qual pertencem. Por outro lado, ressalta que círculos sociais, mesmo compostos por grupos familiares tradicionais, podem ser modificados por indivíduos que mantiveram contato e associação com outros grupos.

Para exemplificar seu argumento, Simmel lembra como se deram as transformações vivenciadas pelas classes sociais vinculadas à cultura e à intelectualidade no período renascentista. Para ele, o ideal humanístico daquele período atravessou diferentes grupos e estratos que haviam sido forjados com base na estratificação social segregacionista da sociedade medieval.

Em decorrência do Renascimento Cultural, novas formas de relações e círculos sociais foram criados, possibilitando aos indivíduos diferentes formas de relacionarem-se com a sociedade. Por consequência, a sociedade formada por essas relações tornou-se mais civilizada e complexa, levando Simmel a concluir que "a quantidade de variados círculos então, onde os indivíduos se relacionam e se mantêm, é um indicativo de cultura" (idem, p. 370). Esse autor, inclusive, compreende que quanto mais distante o indivíduo estiver do primeiro círculo social do qual faz parte, o familiar nesse caso, mais culto ele poderá ser.

Sobre a relação entre indivíduo e sociedade, Simmel identifica o desejo do indivíduo em personalizar as formas nas quais se constituem as relações nos círculos sociais, "aquilo que nós chamamos subjetivamente como acordo para proeminência, a personalidade que combina os elementos da cultura dentro de um estilo individual" (idem, p. 372). Contudo, destaca que, para o indivíduo personalizar essas formas, ele também necessitará estar inserido no grupo, sendo, consequentemente, influenciado por ele. Ressalta que nem todos os círculos sociais se estabelecem da mesma forma, inclusive porque cada vez mais os círculos sociais modernos se constituem com base na competição. "Assim, quando uma forte concorrência prevalece dentro de um círculo, os membros buscam para si outros grupos que são menos competitivos para ele" (idem, p. 382).

Para ilustrar essa constatação, Simmel analisa as formas das relações que se estabelecem entre os membros de clubes da aristocracia. Nesses clubes, os aristocratas procuram manter uma concorrência interna fraca em termos de posições políticas e demonstrações de riqueza, ao mesmo tempo em que fortalecem a prática esportiva como principal foco das

2 Para esses seres miseráveis, que não são de todo capazes de uma forma de associação realmente racional, tais agrupamentos por dualidade de afiliação, tão nitidamente separados, dirigidos de maneira horizontal e vertical, devem significar um enriquecimento no sentimento de estar vivo, um alongamento provavelmente inacessível e, portanto, que possa dobrar a existência. 
atenções. Assim, as disputas dentro do clube se valem das competições esportivas como formas metafóricas de disputas por poder, evitando conflitos mais diretos e mantendo a coesão e fortalecimento do grupo.

Outra forma de interseção se dá quando indivíduos possuem interesses opostos uns aos outros, mas pertencem a um mesmo grupo político. Simmel percebe que, embora esses indivíduos se identifiquem com interesses diferentes, o fato de fazerem parte de um grupo político centralizado ou conservador poderá promover o surgimento de novos grupos dentro do grupo maior e, assim, representarem interesses específicos. Posteriormente, a tendência é que haja uma busca por alianças (interseções entre os interesses) entre esses novos grupos, na expectativa de que eles se fortaleçam contra o poder central.

Outro exemplo significante para consolidar a argumentação simmeliana são as formas de afiliação religiosa. Simmel lembra que as formas de interseção estabelecidas entre a cultura anciã, a semita e a greco-romana basearam-se no vínculo entre a nacionalidade do indivíduo e a cultura local. Depois, porém, a consolidação do cristianismo fez a atitude religiosa deixar de ligar-se apenas ao complexo de laços sociais estabelecidos e vincular-se também à responsabilidade de cada alma individual.

Simmel esclarece que o significado sociológico da religião é o reflexo do seu relacionamento dual com a vida: de um lado, ela é um elemento de oposição a todos os conteúdos de nossa vida mundana por ser tratada como superior; de outro, ela é um elemento associado a todos os outros elementos da vida. "Deus foi incorporado diretamente aos interesses do grupo. Assim, os deveres para com Deus estavam diretamente ligados aos demais deveres" (idem, p. 383).

Há em cada criação de círculos e grupos sociais, nos quais as pessoas estão interessadas nas mesmas coisas, uma compensação para o isolamento da personalidade que emerge e rompe com o confinamento estreito de condições anteriores. Sobre os exemplos utilizados em sua argumentação epistemológica, Simmel explica que

\footnotetext{
todos esses exemplos servem apenas como analogias de combinações e desenvolvimento sociológicos para mostrar que, neles, formas universais e normas permanecem amplamente no reino da sociologia. Forma e conteúdo são apenas conceitos relativos, categorias de conhecimento para a gestão de fenômenos e sua organização intelectual (idem, p. 393).
}

Refletindo sobre a diversidade de características que as relações sociais podem desenvolver, compreendemos que a observação das interseções e redes de interdependência propicia ao cientista social uma melhor compreensão sobre as características das relações entre indivíduos e sociedades. Nesse sentido, devemos analisar a dinâmica de relações que caracterizam a cultura organizacional escolar como reflexo da influência da ação dos indivíduos que a compõem, como reflexo da influência que a estrutura social exerce sobre ela, ou analisá-la como um elemento intermediário que reflete tanto a influência da ação individual quanto a influência da estrutural social? 


\section{OrganizaÇões Escolares: Figurações intermédias entre a Estrutura e A AÇÃo}

Na medida em que as relações sociais foram se tornando mais complexas, em especial nas sociedades que passaram por processos ligados à industrialização, urbanização e modernidade, o sociólogo alemão Norbert Elias (1994) observou que passava a ser comum que, entre os indivíduos, houvesse uma maior valorização da sua identidade-eu do que da sua identidade-nós. Para esse importante referencial teórico, o que faria o indivíduo pender mais para um lado de valorização do que para o outro seria o estágio de organização da sociedade na qual ele está inserido.

Em sua concepção epistemológica, Elias percebe que sociedade significa uma rede de funções que os indivíduos são levados a formar no interior das associações humanas, estabelecendo interdependência entre as relações interindividuais. Baseados em sua concepção, passamos a perceber que cada vez mais as organizações sociais foram ganhando forma e importância diferenciadas, o que as obrigou a passarem por constantes processos de mudança e colocou-as como representativos elos de interdependência para as relações sociais.

Sendo compostas por indivíduos, mas ao mesmo tempo estando vinculadas a estruturas sociais, processos de mudança podem implicar dificuldades para muitos dos integrantes de uma organização, já que muitos deles podem ter alcançado uma relativa zona de conforto e, por isso, recusam-se não só a adaptar-se como também a conhecer um novo processo.

Entendemos, porém, que, embora projetos ou políticas públicas voltadas à mudança organizacional sejam formulados de maneira propositiva, ou seja, de maneira a contribuir com o desenvolvimento da organização e de seus membros, nem sempre, ao passar da teoria para a prática, o que fora planejado se configurará de maneira condizente com a realidade com a qual se relaciona. Com efeito, organizações inseridas em uma mesma estrutura administrativa, por serem divididas em unidades distintas e administradas por diferentes indivíduos, operam a mesma diretriz de maneira diferente de outras unidades em decorrência da especificidade de suas características socioprofissionais.

Assim, por mais que determinada administração estatal procure estabelecer um sistema de padronização das atividades em sua rede, questionamos se ela não estará sempre sujeita às diferentes formas de funcionar de cada uma de suas unidades. Ou seja, perguntamos se, por conta da dinâmica dos processos sociais que envolvem seus diferentes integrantes, cada uma das organizações não desenvolverá a própria cultura organizacional.

E é a partir dessa reflexão que procuramos entender como a cultura organizacional estabelecida em uma organização escolar se apropria e é capaz de viabilizar os processos vinculados à implementação de políticas públicas educacionais. Mais especificamente, propomo-nos a realizar uma sociologia das organizações que compõem o campo educacional do Brasil e Portugal, procurando averiguar como a cultura organizacional, forjada nas unidades de ensino, foi capaz de influenciar as formas de apropriação e viabilização da política de gestão democrática da educação. 
Compreendemos que, naquilo que envolve as dinâmicas socioprofissionais que compõem o campo educacional, é decisivo o papel que cada escola e seu diretor passam a ter na relação que se estabelece entre Estado e comunidade escolar, sendo os mesmos identificados como elementos intermediadores dessa relação. Percebemos que a escola, enquanto organização física que é, também pode passar por práticas de gestão específicas e incongruentes com uma gestão democrática. Nessa figuração, verificamos que nela há a representação do diretor como exemplo de mediação entre a agência e a estrutura e, dependendo da postura adotada por esse elo mediador, a escola poderá se constituir enquanto espaço de reprodução do exercício autoritário do poder, ou como um espaço de estímulo à autonomia individual e profissional, o que não é concebível.

As ações, comportamentos, escolhas ou aspirações individuais do diretor são também uma questão de produtos da relação que se estabelece entre as pressões e estímulos da conjuntura social na qual ele está inserido. Ele é o único indivíduo que goza de acesso e interlocução mais constante e representativa entre as organizações do campo educacional estatal - nesse caso, entre as escolas e órgão estatais -, ou seja, entre os distintos espaços de poder.

Notamos que, enquanto diretor, ele sofre influência da estrutura sociopolítica à qual está vinculado e é representada pela administração estatal da educação, mas que, ao mesmo tempo em que é um indivíduo, o diretor também influencia os profissionais ligados à escola que dirige. Dessa forma, passamos a entendê-lo como um elo, um nível intermediário entre as esferas organizacionais, podendo se mover entre uma figuração e outra.

O diretor escolar constitui centro das atenções de nossa análise, haja vista a sua capacidade de intermediar as relações entre órgão governamental e unidades escolares. Os papéis exercidos por esse ator social nos remetem à observação de Piotr Stompka (2005), quando analisa a sociologia que ele classifica como de nível intermediário. Para esse autor, nessa concepção sociológica, "não existem agentes sem estruturas nem estruturas sem agentes, ao mesmo tempo em que as estruturas não se dissolvem nos agentes e os agentes não se dissolvem nas estruturas" (idem, p. 368).

A representação do diretor escolar junto aos distintos espaços organizacionais com os quais se relaciona nos remete a um importante representante da corrente sociológica citada acima, o sociólogo Norbert Elias (1994). Em sua obra, Elias nos apresenta o conceito de Figurações, concebendo-as como a configuração de relações complexas de interdependência que cobrem o hiato entre ação e estrutura, uma vez que os indivíduos constituem figurações históricas e são historicamente constituídos por elas.

Teia de relações de indivíduos interdependentes que se encontram ligados entre si a vários níveis e de diversas maneiras. [...] as ações de um conjunto de pessoas interdependentes interferem de maneira a formar uma estrutura entrelaçada de numerosas propriedades emergentes, tais como relações de força, eixo de tensão, sistemas de classes e de estratificação, desportos, guerras e crises econômicas (ELIAS; DUNNING, 1985). 
Em oposição à hegemônica concepção estruturalista do início da Sociologia, Elias não entende a sociedade tal qual um organismo que rege os indivíduos por atributos coercitivos como forma de orientação do comportamento, mas a partir da concepção epistemológica de interdependência entre os indivíduos. Ele defende que a ligação entre diversos indivíduos e organizações dá origem a configurações diversas as quais, relacionadas, imbricam-se numa teia de interdependência. Assim, figuração é um termo que pode entender as relações sociais as quais se constituem interligadas por meio de transações entre atores envolvidos em diferentes conjunturas sociais (ELIAS, 1978).

No que denomina de Teoria Sociológica dos Processos, Elias destaca que as mudanças sociais e históricas de cada sociedade devem ser o viés analítico da teoria sociológica, a partir de uma abordagem sociológica-processual. Para esse autor, a fim de entender-se a relação entre indivíduo e sociedade se deveria levar em consideração a psicogênese e a sociogênese dos processos sociais que a constitui.

Por psicogênese, Elias entende ser a dimensão voltada ao comportamento e estrutura de personalidade dos indivíduos, enquanto que a sociogênese diz respeito às formas específicas com as quais sociedades, Estados e nações se desenvolveram. Uma dimensão está diretamente vinculada à outra, e a compreensão da maneira como se dá o entrelaçamento das duas é a chave para a teoria sociológica processual. Essa análise, porém, não condiciona a influência de uma dimensão sobre a outra, tampouco que o entrelaçamento dessas dimensões ocorre de forma causal, linear ou evolutiva, pois o que se analisa são processos.

$\mathrm{O}$ estudo desses processos sociais deve considerar os atos e vontades dos planos de muitos seres humanos que, por sua vez, resultam de configurações sociais particulares. Eles indicam transformações amplas, contínuas e de longa duração, pois, "diferentemente do processo biológico de evolução, os processos sociais são reversíveis" (ELIAS, 2006, p. 28).

Assim, cada vez mais os indivíduos tendem a se agrupar em contextos socioculturais particulares em virtude da interdependência que se estabelece entre eles. Para Elias, os seres humanos formam figurações uns com os outros, entre grupos sociais pequenos ou grandes. Figuração, então, seria um instrumento conceitual mais adequado ao entendimento da realidade social e apresenta-se como alternativa ao dilema da sociologia: "aqui o indivíduo, ali a sociedade" (idem, p. 23).

Dito de outra maneira: um ser humano singular pode possuir uma liberdade de ação que lhe permita desligar-se de determinada figuração e introduzir-se em outra, mas se e em que medida isto é possível depende de fato das particularidades da figuração em questão (idem, ibidem).

A concepção epistemológica de Elias apresenta às Ciências Sociais uma sociologia figuracional e processual, na qual o estudo das relações sociais se realiza a partir da congruência existente entre micro e macrossociologia. A partir dessa concepção, entende-se que cada configuração social influenciará a vida dos grupos, sua organização familiar, a relação entre os vizinhos, a ocupação de empregos e cargos, o envolvimento com a criminalidade e tantas outras situações que se desenvolvem em meios sociais. 
Norbert Elias (1990), a partir da obra O Processo Civilizador, passou a dar mais ênfase à relação do indivíduo com os processos sociais do que propriamente à relação do indivíduo com a macroestrutura social. Não que o tema não continuasse a fasciná-lo, mas porque essa relação mudou consideravelmente na sociedade contemporânea. Esse autor constatou que, à medida que as sociedades se tornam mais complexas, mais desenhos de normas sociais se delineiam e, consequentemente, evidenciam-se mais possibilidades de forjar-se um conceito de indivíduo, uma vez que essas normas são construídas e redimensionadas o tempo todo, sendo a historicidade de cada sociedade a chave para a compreensão sociológica.

Analisando a teoria social à sua época, Elias identificou a existência de dois eixos que buscam explicar o conceito de sociedade: num primeiro, entende-se a sociedade a partir da conjunção de formações sócio-históricas que podem ser representadas pelas suas instituições e organizações sociais bem como pelos indivíduos que as criam e controlam; no segundo, despreza-se a abordagem que leva em conta as formações históricas e sociais, pois se considera que o indivíduo não desempenharia papel algum e a sociedade é concebida como uma entidade orgânica supraindividual.

Para Elias, sociedade significa uma rede de funções que os indivíduos são levados a formar no interior das associações humanas, estabelecendo interdependência entre as relações interindividuais. No curso do processo de civilização e no desenvolvimento das sociedades mais complexas de nossos dias, os indivíduos passam a se regular cada vez mais conforme coações exteriores que se ampliam à autocoações. Uma das formas de regulação se dá quando o desenvolvimento do Estado se faz mostrar a nação e sociedade com os quais o indivíduo convive ou conviveu (sociogênese). Na inter-relação sociedade e indivíduo se consolidam regulações endógenas ao indivíduo (psicogênese), as quais, muitas vezes, são mais eficazes, pois tratam de autocontrole e punição acionados por valores éticos e morais que agem no e sobre o indivíduo, esteja onde estiver.

A análise dessas dimensões foi muita válida para a elaboração da obra Os Alemães (1997). Nesse trabalho, Elias apresenta uma narrativa histórico-sociológica do que envolveu os processos sociais do seu país natal, a Alemanha. Sua análise parte da devastação causada àquela sociedade por guerras e conflitos armados no século XVII e vai até os processos que a levaram à ascensão do nazismo no século XX - o que o obrigou a se exilar em outros países do continente europeu.

Dentre outros processos relevantes que caracterizam o intervalo de tempo pesquisado, Elias destaca a lentidão do processo de reunificação dos territórios alemães (fim do século XIX), o enfraquecimento do Estado alemão em decorrência da derrota na Primeira Guerra Mundial e do fenômeno socioprocessual, o surgimento e fortalecimento - por meio de forte propaganda e atos terroristas - de grupos autoritários oponentes ao governo republicano anterior à ascensão do nazismo ao poder.

Segundo Elias, todos esses processos se interligaram ao habitus nacional alemão, forjado no espírito guerreiro da nobreza responsável pela unificação dos territórios identificados num estágio inicial de civilização que poderiam tê-la levado a tornar-se uma sociedade de corte, tal qual a francesa. Na Alemanha, ao contrário, imperava a aceitação do uso da 
força e da violência como mecanismos mais eficientes para resolver problemas comuns à área política e social.

Consequentemente, a resolução de conflitos externos à Alemanha também passou a ser concebida a partir da utilização desses mecanismos. Não por acaso, em uma conjunção de entrelaçamentos única, grupos sociais e indivíduos alemães forjaram um Estado autoritário, belicista, ultranacionalista e segregacionista que, por sua vez, guiou o país, fazendo-o tornar-se o principal protagonista da Segunda Guerra Mundial, a maior guerra, até então, de todos os tempos.

Preocupado em desenvolver sua sociologia histórica, em sua obra Sobre o Tempo (1998), Elias apresenta o relógio como exemplo de instrumento usado para facilitar o controle mais harmônico de pessoas e suas atividades interdependentes em redes de relações sociais. "Os relógios são, em seu uso cotidiano pelas sociedades, primordialmente instrumentos para coordenar à distância as atividades de muitas pessoas capazes de um grau relativamente elevado de autocontrole" (ELIAS, 1998, p. 15).

Como especialistas em um mundo de atividades especializadas, o relógio se coloca para os indivíduos como um elo de interdependência de rede de relações que se estabelecem à medida que as relações sociais se tornam mais complexas, levando os indivíduos a recorrerem ainda mais uns aos outros. À proporção que isso acontece, aumenta a necessidade de determinarem-se sucessões de acontecimentos devido à lembrança do que já acontecera, definindo-se padrões que podem servir como comparações (idem, p. 13).

O tempo, em si, pode ser entendido como um aspecto do processo civilizador por meio do qual se procuram ordenar as diferentes sociedades e os diferentes grupos e organizações que delas fazem parte e não menos um mecanismo de coação externa à auto-coação. A partir do viés sociológico, Norbert Elias procura superar os hiatos de interpretação sobre o tempo, criticando aquelas que foram realizadas pelas abordagens filosóficas, naturalistas e históricas. Percebe que o tempo, na verdade, nada mais é do que um constructo humano, civilizador entre natureza e sociedade e exerce coerções que interligam estruturas psicológicas às estruturas sociais mais amplas.

A palavra "tempo" seria, então, símbolo da relação que um grupo humano estabelece entre dois ou mais processos, dentre os quais um deles é entendido como referência ou medida para os demais. O tempo exerce coerções que interligam estruturas psicológicas a estruturas sociais mais complexas, contribui para a previsão da intrigante cadeia de relações sociais e para regulá-las, afetando a ação de cada pessoa, pois quanto maior e interdependente for essa ação, maior será sua dependência do tempo.

Assim como o relógio, o calendário também se coloca como um exemplo de elo de interdependência em rede. Com ele, as organizações e os indivíduos que delas fazem parte podem pensar a partir de cadeias de associações interligadas. Eles podem pensar sobre cronogramas de atividades, a exemplo de férias programadas, e sobre suas diversas atividades de planejamento e estratégia interligadas, já que fazem parte de uma mesma rede. Por isso, Elias pergunta: com que objetivo os homens necessitam determinar o tempo? 
mais intensamente à medida que envelhecemos - a fuga dos anos nos calendários. Tudo isso se tornou uma segunda natureza e é aceito como se fizesse parte do destino de todos os homens. E esse processo cego continua seguindo pelo mesmo rumo, sobretudo, se bem que não em caráter exclusivo, no caso das funções superiores de coordenação social, onde a interseção de um número cada vez maior de cadeias de interdependência incita os homens a submeterem sua atividade profissional a um horário cada vez mais exato (ELIAS, 1998, p. 11).

$\mathrm{Na}$ concepção eliasiana, as explicações sociológicas devem observar as conexões de relacionamentos que envolvem o indivíduo tal qual uma teia, composta por uma rede de indivíduos. As sociedades seriam compostas de forma que os indivíduos fossem os responsáveis pela socialização de suas partes componentes em um contínuo processo em que todos estão em constante relação uns com os outros.

Na obra Os estabelecidos e os outsiders (2000), Elias objetiva compreender a lógica da configuração social e das relações de interdependência que se verificam entre indivíduos em uma pequena cidade industrial no centro da Inglaterra. Por meio do uso de fontes diversas - estatísticas, entrevistas, documentos e etnografia -, ele identifica os laços de interdependência que unem, separam e classificam os indivíduos e grupos sociais segundo a importância deles em relação à luta pelo poder e sua manutenção.

Sua análise considera as variáveis ligadas à violência enquanto mecanismos sociais de discriminação e exclusão utilizados como elementos de diferenciação entre os grupos de habitantes da cidade. Essas características se apresentaram como problema de pesquisa, uma vez que o pensador alemão percebeu que, caso um pesquisador comum adotasse para sua pesquisa apenas variáveis sociais clássicas - tais como renda, etnia, escolaridade ou faixa etária -, não perceberia a diferença entre os indivíduos ligados ao grupo de estabelecidos e aqueles inseridos no grupo de outsiders. Isso porque Elias constatou que os elementos de distinção entre os grupos se apresentavam principalmente no discurso sobre a "genuinidade nativa" que os grupos anteriormente estabelecidos na região evocavam para si mesmos em detrimento dos recém-chegados em busca de oportunidades.

Dessa constatação, apreendemos que Elias procura iluminar os diferenciais de integração entre grupos aparentemente semelhantes, analisando a interação social entre eles. A fim de entender as relações de poder estabelecidas naquela região, segundo as normas de socialização constituídas por cada grupo, esse pensador volta sua atenção à história dos verdadeiros atores sociais por meio da observação participante.

Para Elias, fazia-se importante dar relevância à herança histórico-sociológica daqueles indivíduos e comunidade. Cada família procurava se envolver numa teia de relações compostas por regras determinadas e rígidas de um lado, mas também por necessidades e escolhas individuais de outro lado. Uma vez constituída tal rede de relações também se permite aos indivíduos a possibilidade de promoverem a mudança social. Essa mudança pode se dar por meio de trocas diretas e indiretas, e de apoio ou retaliação aos que fazem parte da sua rede social (estabelecidos), levando aqueles que dela não fazem parte a procurarem adequar-se aos códigos dominantes, mesmo que eles se vejam como outsiders. 
Aliás, o conceito de mudança é muito caro ao trabalho de Elias. Para ele, os processos de mudança social são inerentes a todas as figurações e, também por conta disso, o sociólogo deve ater-se não só as particularidades de cada contexto figuracional como também aos processos históricos que o forjaram.

Já citado neste trabalho, Piotr Stompka (2005) também classifica Elias a partir do que ele chama de sociologia histórica. Ressalta que, diferentemente dos sociólogos à época de Elias, "ele é um dos primeiros sociólogos históricos a mover um ataque persistente contra o refúgio dos sociólogos no presente" (STOMPKA, 2005, p. 352). Sobre essa característica da sociologia histórica, o sociólogo polonês destaca a seguinte afirmação de Elias:

O antídoto para a falaciosa abstração da constituição diacrônica e dinâmica da sociedade humana é encontrado na perspectiva processual, no reconhecimento de que o presente imediato no qual os sociólogos estão se refugiando é somente uma fase curta e fugaz na vasta cadeia do desenvolvimento da humanidade, a qual, vinda do passado, desemboca no presente e estende-se à frente na direção de possíveis futuros (ELIAS apud STOMPKA, 2005, p. 352).

Com a teoria histórica, processual e figuracional eliasiana, a mudança deixa de ser necessariamente algo superior e coercitivo, e passa a ser compreendida como inerente às relações sociais. Embora imprevisível, no sentido de se poder garantir como e quando ela vai ocorrer, a mudança é compreendida por Elias como reflexo de contextos particulares de relações interdependentes interligadas por pontos nodais, ou seja, figurações.

Para a compreensão de pontos nodais na concepção de Elias, lembramos a metáfora utilizada por ele para explicar a balança nós-eu, e que faz referência ao processo de complexificação das relações sociais, já comentado neste tópico. Elias explica que os pontos nodais podem ser representados tanto por atores individuais como também por grupos e até Estados. As figurações formam um "entramado flexível de tensões, um equilíbrio elástico e flutuante, uma balança de poder que se move de e para, inclinando-se primeiro para um lado, depois para o outro" (idem, ibidem).

Esses movimentos imprevisíveis, específicos, mas também inerentes às relações estabelecidas nas figurações e desenvolvidos por indivíduos e grupos em interdependência, apresenta-se como uma concepção epistemológica importante ao nosso trabalho. Observemos que, por tratarmos da implementação de políticas públicas e dos processos sociais que as envolvem, também nos debruçamos sobre os processos que envolvem mudanças. Essas mudanças podem refletir-se tanto no comportamento de cada indivíduo quanto na constituição da cultura das organizações escolares pesquisadas.

Forjadas em contextos ditatoriais, essas figurações precisaram adequar-se ao processo de democratização social das décadas de 1970 e 1980, em Portugal e no Brasil, respectivamente. Contudo, como já indicamos, esse processo de mudança enfrenta um novo processo de transformação, principalmente quanto à implementação das políticas atuais de lista tríplice no campo educacional pernambucano e de agrupamento de escolas, no campo educacional português. 
Ora, considerando que, conforme Elias, para identificar se o processo de mudança social se estabeleceu de fato seria necessário observar seus desdobramentos com o passar do tempo, ponderamos se já passou o tempo mínimo de três gerações para que os princípios de uma gestão democrática da educação tenham sido incorporados pelos indivíduos e culturas organizacionais dos campos educacionais em análise.

Segundo Elias, as mudanças que ocorrem em cada figuração têm a capacidade de influenciar a vida dos grupos, sua organização familiar, relação entre os vizinhos, ocupação de cargos e outros. Contudo, também cabe à perspectiva sociológica voltar-se à historicidade de cada contexto social, observando, nesse caso, como a influência da mudança se dará com o transcorrer de pelo menos duas ou três gerações consecutivas.

Antes disso e devido à rede de interdependência constituída entre os atores sociais e seus variados tipos de estereótipos inculcados no comportamento cotidiano dos indivíduos e reproduzidos por eles, dificilmente se poderá perceber a constituição de processos de mudança significativos, algo para o qual os sociólogos do presente não atentariam, por negligenciarem a perspectiva processual.

Elias, com propriedade, destaca o fato de: o que seria dos homens se deixassem de planejar? Não haveria processo. Dessa forma, há de compreender que o planejamento existe nas ações e metas previstas pelas figurações humanas, elas são racionais e intencionais, embora os resultados não sejam os desejados.

Considerando a importância de se compreender a influência da cultura organizacional escolar sobre a apropriação e viabilização de políticas públicas, como a de gestão democrática da educação, entendemos que variáveis clássicas de análise sociológica - a exemplo de escolaridade, gênero e faixa etária - devem ser analisadas junto aos processos que determinaram a história de vida dos indivíduos que interagem nas escolas.

Dessa maneira, a possível convivência de muitos desses indivíduos com o período ditatorial fê-los desenvolver possíveis práticas autoritárias em suas relações socioprofissionais ou, ainda, na relação deles com pais e alunos. Por isso, a importância de se dar relevância à sociogênese dos processos que se relacionam com as organizações escolares, vendo os indivíduos como membros de uma teia de relações compostas não só por regras determinadas e rígidas como também por necessidades e escolhas individuais.

\section{Considerações Finais}

A constatação de que cada escola constitui uma cultura organizacional única está longe de ser considerada pelos agentes responsáveis pela elaboração e implementação de políticas públicas. Apesar disso, a implementação de políticas públicas tem a sua viabilização diretamente ligada às formas como ela é apropriada e dinamizada em cada cultura organizacional escolar. Uma das principais constatações de nossa pesquisa de doutorado foi perceber como sociedades que foram governadas por regimes autoritários ainda tinham muitas das características desses regimes presentes na cultura das organizações do campo educacional. 
Notamos que Brasil e Portugal iniciaram seus processos de redemocratização recentemente (décadas de 1980 e 1970, respectivamente) e que os princípios propagados por esses processos passaram a ser incorporados também pela área da educação. Exemplo disso é a implementação da política de Gestão Democrática da Educação nos países.

Verificamos, contudo, que a viabilidade dessa política foi ameaçada pelos processos sociais que envolvem a sua implementação. Diante das realidades já sedimentadas nas organizações dos dois campos educacionais, a política de gestão democrática da educação foi sendo gradativamente influenciada por processos que deram margem à implementação da política de Lista Tríplice no sistema educacional de Pernambuco e à política de Agrupamento de Escolas no sistema educacional português.

Com a política de lista tríplice temos a ruptura de um processo que vinha sendo desenvolvido desde a redemocratização no Brasil. A política de gestão democrática, na década de 2000, havia se fortalecido com a política de escolha do diretor escolar via eleição direta, porém perdeu fôlego porque essa escolha agora está condicionada à aprovação do candidato a diretor em cursos oferecidos exclusivamente pela Secretaria de Educação do Estado e à escolha final por parte do governador.

Quanto à política de agrupamento de escolas, percebemos que, na medida em que ela procura agregar distintas escolas em torno da administração centralizada de uma única escola-sede, tal política termina por tomar as distintas realidades de cada escola do agrupamento como se elas fossem padronizadas e homogêneas, ou seja, não leva em conta as particularidades da cultura organizacional de cada uma delas.

A respeito das organizações escolares pesquisadas, verificamos que elas ainda compartilham culturas organizacionais que mesclam tardias práticas socioprofissionais herdadas dos regimes autoritários com novas demandas sociais influenciadas pela redemocratização. Nesse sentido, a viabilização da política de gestão democrática da educação, da forma como foi apropriada pelas interpretações e práticas de muitos dos atores sociais, também ficou condicionada à prática de gestão individual dos diretores escolares.

Assim, se o diretor apresentasse disposição para gerir a organização escolar de maneira democrática e não encontrasse forte resistência a isso, ele conseguiria desenvolver importantes princípios da política. Já se o diretor não tivesse essa disposição e também não fosse cobrado pelos atores para que a desenvolvesse, a tendência seria que ele viesse a se valer dessas condições para desenvolver uma gestão escolar centralizada.

A partir de nossa pesquisa de doutoramento também validamos a orientação de realizar-se uma análise sociológica da organização escolar que considere a premissa de que ela se encontra inserida em um contexto no qual sofre influência do nível macro, representado pela estrutura administrativa estatal ao qual a escola está submetida, e do nível micro, representado pela ação individual dos atores que a compõem.

As evidências encontradas nos remeteram à sociologia de Norbert Elias, segundo o qual apenas após a passagem de acontecimentos que envolvam duas ou três gerações é que podemos perceber processos efetivos de mudança social. Ao recorrermos à sociologia processual eliasiana, percebemos que ainda há um ranço comportamental não democrático 
nas culturas das organizações escolares dos dois campos educacionais, o qual influencia o processo de apropriação e viabilização de políticas públicas.

Como os dois campos educacionais ainda se encontram no início da segunda geração influenciada pela implementação da política de gestão democrática da educação, percebemos que a mudança social esperada a partir da sua implementação ainda não se manifesta nas práticas socioprofissionais da maioria dos atores.

\section{REFERÊNCIAS}

AGUIAR, Márcia A. Política educacional e planejamento participativo: a experiência dos fóruns itinerantes de educação em Pernambuco. Revista Educação (Porto Alegre, impresso), v. 37, n. 2, p. 201-209, maio-ago, 2014.

BARROSO, J. A regulação das políticas públicas de educação. Espaços, dinâmicas e atores. Coimbra, 2006.

BRASIL. Constituição da República Federativa do Brasil: promulgada em 5 de Outubro de 1988. São Paulo: Saraiva, 1996.

BRASIL. Lei de Diretrizes e Bases da Educação. Lei No 9.394, de 20.12.1996. Publicada no Diário Oficial da União do dia 23.12.1996.

COLLINS, Randall. Quatro tradições sociológicas. Petropólis: Vozes, 2009.

DURKHEIM, Émile. As Formas Elementares da Vida Religiosa. São Paulo: Martins Fontes, 2003.

ELIAS, Norbert. A sociedade dos indivíduos. Rio de Janeiro: Zahar, 1994.

. Escritos e Ensaios. Rio de Janeiro: Zahar, 2006.

. Os estabelecidos e os outsiders: Sociologia das relações de poder a partir de uma pequena comunidade. Rio de Janeiro: Zahar, 2000.

. Sobre o Tempo. Rio de Janeiro: Zahar, 1998.

. Os Alemães. Rio de Janeiro: Zahar, 1997.

. O Processo Civilizador. Rio de Janeiro: Zahar, 1990.

. What is Sociology? New York: Columbia University Press, 1978.

ELIAS, N. e DUNNING, E. Em busca da excitação. Lisboa: Difel, 1985.

FONTES, Breno A. Redes sociais e poder local. Recife: Ed. Universitária, 2012.

GIDDENS, Anthony. A constituição da sociedade. 2 ed. São Paulo: Martins Fontes, 2003.

. The constitution of society: outline of the theory of estructuration. Cambridge,

England: Polity Press, 1985. 
GOFFMAN, E. A representação do eu na vida cotidiana. 14 ed. Petrópolis: Vozes, 2007.

HOMANS, G. C. Social Behavior. Its elementary forms. New York: Harcourt, Brace, 1974.

LIMA, LICÍNIO. Agrupamento de escolas como novo escalão da administração desconcentrada. de Revista Portuguesa Educação, vol. 17, núm. 2, 2004, pp. 7-47.

MARX, K. Para a crítica da economia política do capital. São Paulo: Nova Cultural, 1996.

SIMMEL, Georg. Questões fundamentais da Sociologia. Rio de Janeiro: Zahar, 2006.

. Inquiries into the construction of social forms. Leiden: Brill, 2009.

STOMPKA, Piotr. A sociologia da mudança social. 2 ed. Rio de Janeiro: Civilização brasileira, 2005.

WAIZBORT, Leopoldo. Elias e Simmel. In: WAIZBORT, L. (org.). Dossiê Norbert Elias. São Paulo: EdUSP, 2001, p. 89-111.

WEBER, Max. Ensaios de sociologia. Rio de Janeiro. Ed. LTC, 2002.

LTC, 1913.

. Sobre algumas categorias da sociologia compreensiva. Rio de Janeiro. Ed.

WEBER, Silke. Políticas do ensino fundamental em revista: um debate pela democracia. In: A.O. COSTA (org.). Uma história para contar: a pesquisa na Fundação Carlos Chagas. São Paulo: Anablume, p. 57-90, 2004.

\section{Dados dos Autores:}

\section{Jamerson Kemps Gusmão Moura}

Doutor em Sociologia pela Universidade Federal de Pernambuco. Mestrado em Antropologia (UFPE), experiência profissional à pesquisa científica em instituições de ensino superior nas áreas de Cultura Organizacional, Políticas Públicas, Educação, Sociologia e Antropologia das Organizações; Administração, Relações Socioprofissionais e Gestão da Educação; Processos Sociais, Democracia e Autoritarismo; História, Filosofia e Ética, Filosofia do Direito, Sociologia e Antropologia Jurídica; Metodologia de Ensino/Pesquisa, Educação à Distância e Designer Instrucional, dentre outros temas relacionados. Graduado em História (UFPE), possui formação técnica em Administração pela Faculdade de Ciências da Administração da Universidade de Pernambuco-FCAP/UPE.

Submetido em: 20/08/2017

Aceito em: 16/04/2018 